\author{
Abstracta Iranica \\ Abstracta Iranica Revue bibliographique pour le domaine irano-aryen \\ Volume 37-38-39 | 2018 \\ Comptes rendus des publications de 2014-2016
}

\title{
Donald Whitcomb. « Archaeology in Iran and the Experience of Arthur Upham Pope »
}

Sarah Piram

\section{OpenEdition}

1 Journals

Édition électronique

URL : http://journals.openedition.org/abstractairanica/42729

DOI : 10.4000/abstractairanica.42729

ISBN : 1961-960X

ISSN : 1961-960X

Éditeur :

CNRS (UMR 7528 Mondes iraniens et indiens), Éditions de l'IFRI

Référence électronique

Sarah Piram, " Donald Whitcomb. "Archaeology in Iran and the Experience of Arthur Upham Pope » », Abstracta Iranica [En ligne], Volume 37-38-39 | 2018, document 11, mis en ligne le 10 mars 2018, consulté le 28 septembre 2020. URL : http://journals.openedition.org/abstractairanica/42729 ; DOI : https://doi.org/10.4000/abstractairanica.42729

Ce document a été généré automatiquement le 28 septembre 2020

Tous droits réservés 


\title{
Donald Whitcomb. « Archaeology in Iran and the Experience of Arthur Upham Pope »
}

\author{
Sarah Piram
}

\section{RÉFÉRENCE}

Donald Whitcomb. « Archaeology in Iran and the Experience of Arthur Upham Pope », in Yuka Kadoi (dir.), Arthur Upham Pope and A New Survey of Persian Art, Brill, LeydeBoston, 2016, p. 97-109.

1 Cette contribution est extraite de l'ouvrage Arthur Upham Pope and A New Survey of Persian Art publié à la suite d'un colloque international à l'Art Institute de Chicago (9-10 septembre 2010). Donald Whitcomb s'intéresse ici aux actions d'Arthur Upham Pope (1881-1969) dans le domaine de l'archéologie en Iran, dans les années 1920 et 1930.

2 L'auteur commence par faire un point sur la situation archéologique en Iran au début $\mathrm{du} \mathrm{XX}^{\mathrm{e}}$ siècle, en évoquant le monopole français et les fouilles qui se sont exclusivement concentrées à Suse. Il montre ensuite que ce monopole a connu un certain déclin avec l'arrivée au pouvoir de Reẓā Shāh Pahlavi (r. 1925-1941), coïncidant avec l'arrivée de Pope à Téhéran. Selon Whitcomb, les discours éloquents de Pope ont permis une ouverture du pays aux fouilles étrangères et, surtout, un regain d'intérêt des Iraniens pour leur gloire passée. La création par Pope en 1928 de l'American Institute for Persian Art and Archaeology favorisa le financement de plusieurs missions archéologiques en Iran, comme celles de Frederick Wulsin à Tureng Tepe (1929-1930) ou d'Erich F. Schmidt à Dāmghān (1931-1933).

3 La force principale de Pope résidait dans ses connaissances architecturales, ou plutôt dans une forme de méthodologie qui s'apparente à l'archéologie du bâti. Les prospections aériennes de Schmidt dans le nord-ouest de l'Iran lui ont d'ailleurs permis de nouvelles méthodes de réflexion et une approche scientifique singulière. Schmidt 
est, selon Pope, à l'origine d'une nouvelle archéologie scientifique en Iran. Whitcomb cite même un communiqué de 1930 où Pope qualifie de "totally unskilled people " les personnes ayant fouillé avant Schmidt.

4 Whitcomb termine son article en évoquant le cas des fouilles dites "commerciales", visant exclusivement la vente et l'achat d'antiquités et dont les résultats auraient, selon Pope, mérité d'être mieux étudiés et moins négligés. Ces fouilles à visée commerciale connaissent néanmoins un certain déclin dans les années 1960, ce qui marque encore le début d'une autre phase de modernisation.

\section{AUTEURS}

\section{SARAH PIRAM}

Doctorante en histoire de l'art contemporain, Université Paris-Nanterre 